\title{
An approach to optimize the cost of transportation problem based on triangular fuzzy programming problem
}

\author{
Sapan Kumar Das ${ }^{1}$ (DD
}

Received: 4 May 2021 / Accepted: 7 September 2021 / Published online: 15 October 2021

(c) The Author(s) 2021

\begin{abstract}
In this article, we address a fully fuzzy triangular linear fractional programming (FFLFP) problem under the condition that all the parameters and decision variables are characterized by triangular fuzzy numbers. Utilizing the computation of triangular fuzzy numbers and Lexicographic order (LO), the FFLFP problem is changed over to a multi-objective function. Consequently, the problem is changed into a multi-objective crisp problem. This paper outfits another idea for diminishing the computational complexity, in any case without losing its viability crisp LFP issues. Lead from real-life problems, a couple of mathematical models are considered to survey the legitimacy, usefulness and applicability of our method. Finally, some mathematical analysis along with one case study is given to show the novel strategies are superior to the current techniques.
\end{abstract}

Keywords Fully fuzzy linear programming $\cdot$ Linear fractional programming $\cdot$ Linear programming $\cdot$ Multi-objective linear programming $\cdot$ Triangular fuzzy number $\cdot$ Lexicographic order

\section{Introduction}

One of the most incredibly used methods in real world problems consistent with empirical surveys is linear fractional programming (LFP) problem. LFP problem is lead to an important rule to apply in real life problem such as the financial sector, business, economics, engineering, health care, etc. Various complexities have been raised during LFP problem solution by considering the classical approaches. Linear programming (LP) constitutes a particular case of the LFP where the denominator is taken as the constant function 1. Last few years, many researchers have been developing various methods to solve LFP problem [1-7, 18-22]. Welldefined data which contain a greater cost of information are required for LFP problems. But in real-life problems, the precision of data is overwhelming deceitful and this affects the optimal solution of LFP problems. Probability distributions failed to transact with inaccurate and unclear information. Prediction is an important work in the early stage of decision making. Accurate prediction is one of the necessary conditions for correct decision making and is of vital guid-

Sapan Kumar Das

cool.sapankumar@gmail.com

1 Department of Revenue, Ministry of Finance, New Delhi, India ing significance to decision making. In the real-life problem (industrial sector), due to the rapid, electricity, fierce, destructive, far-reaching and other characteristics of real-life, the impact of decision-making mistake is often more serious. The correctness of decision-making is directly related to the success or failure of the current and future practical problem, so making a reasonable decision is crucial to the practical problem. To better guide in the practical situation and make correct practical strategy, fuzzy numbers play an important role to represent the ambiguous data. LFPP with fuzzy numbers termed as fuzzy linear fractional programming problem (FLFPP) being a powerful mathematical tool can model such situations efficiently.

The notion of fuzzy set was pioneered by Zadeh [8] and since then it has been found extensive applications in various fields. Various researchers have dedicated their endeavor to the arena of fuzzy LFP (FLFP) models and fully fuzzy LFP (FFLFP) models [9-13]. Many researchers have also keen to interest to use the lexicographic technique to solve FFLP problems [13, 14, 17]. Fuzzy logic has also been applied in medical science like in heart disease and diabetes prediction [30, 31]. Das et al. [16]. proposed a technique for taking care of the FFLFP issue into a multi-objective LFP (MOLFP) issue by utilizing lexicographic requesting, which is considered as a definite ideal arrangement of the FFLFP issue viable. By using lexicographic technique the crisp LFP 
issue is changed over to a crisp LP issue with the assistance of Charnes-Cooper strategy and that can be explained utilizing the standard simplex technique. Here, we rearrange the LFP issues got from the proposed approach by Das et al. [16]. We consider all the parameters are non-negative triangular fuzzy numbers. Das et al.'s [15] have proposed another method to solve FFLFP problem based on multi-objective LFP problem. Multi-target fuzzy linear fractional programming (MOFLFP) issue is concerned with simultaneous optimization of multiple objective functions, where every target is in the form of a FLFP problem.

The fundamental commitments of this paper are summed up as follows:

- We present another strategy to tackle FFLFP issues using lexicographic technique ordering triangular fuzzy numbers in which all the parameters are non-negative triangular fuzzy umbers.

- According to our new method, FFLFP issue is changed into a multi-target LFP issue (MOLFP) with three objective functions.

- The LFP issue is changed over into crisp LP problem by using change strategy and that can be solved with the conventional simplex techniques.

- The ideal arrangements of these issues give the fluffy ideal arrangement of fresh LP viable.

- A genuine issue is illuminated by the proposed strategy.

- We show that the proposed method is very simple and computationally more effective than existing strategies ordinarily utilized in the writing.

\section{Motivation}

Fuzzy sets, play an important role in uncertainty modeling. The development of uncertainty theory plays a fundamental role in the formulation of the real-life scientific mathematical model, structural modelling in engineering field, medical diagnoses problem, etc. Recently, a question will come up, how can we convert a FLFP equivalent to a crisp number in the logical and scientific way? Several works has been already published in FLFP arena till now and the need of Crispification is also explained in dissimilar articles. How can we implement it in a linear programming based operation research problem? Is it possible to apply in real life problem? Still there is no method for applying in linear fractional programming problem having triangular fuzzy numbers with less complexity. From this aspect we try to extend this research article.

Staying of this paper is summarized as follows: "Preliminaries" surveys the essentials of fuzzy sets and fuzzy numbers utilized all through the article. In "Das et al.'s method [16]", the proposed technique by Das et al. [16] is improved dependent on the lexicographic strategy of trian- gular fuzzy numbers. In "Proposed approach" arrangements with the proposed technique to take care of FFLFP issues. Focal points of the proposed technique over the current strategies for taking care of fuzzy FP issues are examined in "Numerical model" and "Case study".To show the utilization of the proposed method a genuine issue is established in "Example 6.1: Transportation problem [16]" and is trailed by the finishing up comments "Advantages of proposed method and result analysis".

\section{Preliminaries}

In this section, we have introduced some fundamental idea of fuzzy triangular number, which was valuable in this paper.

Definition 2.1 [16] Let $Z$ signifies a universal set. At that point a fuzzy subset $\tilde{A}$ of $Z$ is characterized by its enrollment $\mu_{\tilde{A}}: Z \rightarrow[0,1]$; which doled out a genuine number $\mu_{\tilde{A}}(Z)$ in the span $[0,1]$, to each component $z \in Z$, where the estimations of $\mu_{\tilde{A}}(Z)$ shows the evaluation of participation of $\mathrm{z}$ in $\tilde{A}$. A fuzzy subset $\tilde{A}$ can be described as a lot of requested sets of component $z$ and grade $\mu_{\tilde{A}}(Z)$ and is regularly composed $\tilde{A}=\left(z, \mu_{\tilde{A}}(z)\right): z \in Z$ is known as a fuzzy set.

Definition 2.2 [16] A fuzzy number $\tilde{A}=(d, e, f)$ is supposed to be a triangular fuzzy number if its membership function is given by:

$$
\mu_{\tilde{A}}(Z)= \begin{cases}\frac{(z-d)}{(e-d)}, & d \leq z \leq e, \\ \frac{(f-z)}{(f-e)}, & e \leq z \leq f, \\ 0, & \text { else. }\end{cases}
$$

Definition 2.3 A triangular fuzzy number $(d, e, f)$ is supposed to be non-negative (non-positive) triangular fuzzy number if just if $d \geq 0(f \leq 0)$.

Definition 2.4 [15] Two triangular fuzzy number $\tilde{A}=(d, e$, $f)$ and $\tilde{B}=(g, h, i)$ are supposed to be equivalent, if and just if $d=g, e=h, \quad f=i$.

Definition 2.5 [2] A ranking is a function $R: F(R) \rightarrow R$ where $F(R)$ is a set of fuzzy number defined on set of real numbers, which maps each fuzzy number into the real line, where a characteristic request exists. Let $\tilde{A}=(d, e, f)$ is a triangular fuzzy number then $\mathfrak{R}(\tilde{A})=\frac{d+2 e+f}{4}$.

Definition 2.6 [16] Let $\tilde{A}=(d, e, f), \tilde{B}=(g, h, i)$ be two triangular fuzzy numbers then the fuzzy math is characterized as follows:

(i) $\tilde{A}+\tilde{B}=(d, e, f)+(g, h, i)=(d+g, e+h, f+i)$, 
(ii) $-\tilde{A}=(-f,-e,-d)$,

(iii) $\tilde{A}-\tilde{B}=(d, e, f)-(g, h, i)=(d-i, e-h, f-g)$,

(iv) Let $\tilde{A}=(d, e, f)$ be any triangular fuzzy number and $\tilde{B}=(g, h, i)$ be a non-negative triangular fuzzy number then one may have,

$$
\tilde{A} \otimes \tilde{B}=\tilde{A} \tilde{B}=\left\{\begin{array}{l}
(d g, e h, \text { fi }) \quad \text { if } d \geq 0, \\
(d i, e h, \text { fi }) \quad \text { if } d<0, f \geq 0, \\
(d i, e h, e i) \quad \text { if } e<0,
\end{array}\right.
$$

(v) Division: Let $\tilde{A}=(d, e, f)$ be any triangular fuzzy number and $\tilde{B}=(g, h, i)$ be a non-negative triangular fuzzy number then one may have,

$$
\frac{\tilde{A}}{\tilde{B}}=\frac{d}{i}, \frac{e}{h}, \frac{f}{g} .
$$

Remark 2.7 Let $\tilde{A}=(d, e, f), \tilde{B}=(g, h, i)$ be two triangular fuzzy numbers. We state that $\tilde{A}$ is moderately not exactly $\tilde{B}$, if and just if:

- $d<g$ or

- $d=g$ and $(d-e)=(g-h)$ or

- $d=g, \quad(d-e)=(g-h)$ and $(f+d)=(i+g)$.

Note: It is clear from Definition 2.7 that $d=g, \quad(d-e)=$ $(g-h)$ and $(f+d)=(i+g)$ if and only if $\tilde{A}=\tilde{B}$.

\section{Das et al.'s method [16]}

In this section, we consider the model of FFLFP issue in which the parameters, constraints and variables are triangular fuzzy numbers. Supposing examine an overall arrangement of completely fuzzy LFP problem as follows:

$\operatorname{Max} \tilde{Z}_{0}=\frac{\tilde{c}_{0}^{t} \tilde{x}_{0}+\tilde{q}_{0}}{\tilde{d}_{0}^{t} \tilde{x}_{0}+\tilde{r}_{0}}$

S.t. $\tilde{A}_{0} \tilde{x}_{0} \leq \tilde{b}_{0}$

$\tilde{x}_{0} \geq 0$.

To start with, we change model (1) in to a completely fuzzified LP issue utilizing Charnes-Cooper change [1], and acquire the accompanying issue:

$\operatorname{Max} \tilde{c}_{0}^{t} \tilde{y}_{0}+\tilde{q}_{0} \tilde{t}_{0}$

Subject to $\tilde{A}_{0} \tilde{y}_{0}-\tilde{b}_{0} \tilde{t}_{0} \leq \tilde{0}$,

$\tilde{d}_{0} \tilde{y}_{0}+\tilde{r}_{0} \tilde{t}_{0} \leq \tilde{1}$,

$\tilde{y}_{0}, \tilde{t}_{0} \geq 0$.
Considering all the parameters $\tilde{x}_{0}, \tilde{c}_{0}, \tilde{q}_{0}, \tilde{d}_{0}, \tilde{r}_{0}, \tilde{b}_{0}$ and $\tilde{z}_{0}$ are described as a triangular fuzzy numbers $\left(\left(x_{0}\right)^{p},\left(x_{0}\right)^{q}\right.$, $\left.\left(x_{0}\right)^{r}\right),\left(\left(c_{0}^{t}\right)^{p},\left(c_{0}^{t}\right)^{q},\left(c_{0}^{t}\right)^{r}\right),\left(\left(q_{0}\right)^{p},\left(q_{0}\right)^{q},\left(q_{0}\right)^{r}\right),\left(\left(d_{0}^{t}\right)^{p}\right.$, $\left.\left(d_{0}^{t}\right)^{q},\left(d_{0}^{t}\right)^{r}\right),\left(\left(b_{0}\right)^{p},\left(b_{0}\right)^{q},\left(b_{0}\right)^{r}\right),\left(\left(r_{0}\right)^{p},\left(r_{0}\right)^{q},\left(r_{0}\right)^{r}\right)$ and $\left(\left(a_{0}\right)^{p},\left(a_{0}\right)^{q},\left(a_{0}\right)^{r}\right)$, respectively. We put our definition 2.2 and 2.3, the model of Eq. (2) may be rewritten as:

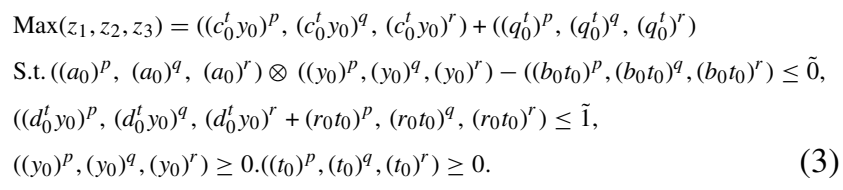

We approach a method for understanding FFLFPP can be summed up as:

Step 1: Utilizing the Definitions 2.2 and 2.3 the model (3), may be written as:

$\operatorname{Max}\left(\left(c_{0}^{t} y_{0}+q_{0} t_{0}\right)^{p},\left(c_{0}^{t} y_{0}+q_{0} t_{0}\right)^{q},\left(c_{0}^{t} y_{0}+q_{0} t_{0}\right)^{r}\right)$

S.t.

$\left(\left(a_{0} y_{0}\right)^{p},\left(a_{0} y_{0}\right)^{q},\left(a_{0} y_{0}\right)^{r}\right)-\left(\left(b_{0} t_{0}\right)^{p},\left(b_{0} t_{0}\right)^{q},\left(b_{0} t_{0}\right)^{r}\right) \leq \tilde{0}$, $\left(\left(d_{0}^{t} y_{0}+r_{0} t_{0}\right)^{p},\left(d_{0}^{t} y_{0}+r_{0} t_{0}\right)^{q},\left(d_{0}^{t} y_{0}+r_{0} t_{0}\right)^{r}\right) \leq \tilde{1}$,

$\left(\left(y_{0}\right)^{p},\left(y_{0}\right)^{q},\left(y_{0}\right)^{r}\right) \geq 0 . \quad\left(\left(t_{0}\right)^{p},\left(t_{0}\right)^{q},\left(t_{0}\right)^{r}\right) \geq 0$.

Step 2: Using the definition 2.4, the model (4) can be presented as:

$\operatorname{Max}\left(\left(c_{0}^{t} y_{0}+q_{0} t_{0}\right)^{p},\left(c_{0}^{t} y_{0}+q_{0} t_{0}\right)^{q},\left(c_{0}^{t} y_{0}+q_{0} t_{0}\right)^{r}\right)$

S.t.

$$
\begin{aligned}
& \left(a_{0} y_{0}\right)^{p}-\left(b_{0} t_{0}\right)^{r} \leq 0, \\
& \left(a_{0} y_{0}\right)^{q}-\left(b_{0} t_{0}\right)^{q} \leq 0, \\
& \left(a_{0} y_{0}\right)^{r}-\left(b t_{0}\right)^{p} \leq 0, \\
& \left(d_{0}^{t} y_{0}+r_{0}\right)^{p}+t_{0}^{p} \leq 1, \\
& \left(d_{0}^{t} y_{0}+r_{0}\right)^{q}+t_{0}^{q} \leq 1, \\
& \left(d_{0}^{t} y_{0}+r_{0}\right)^{r}+t_{0}^{r} \leq 1, \\
& \left(y_{0}\right)^{q}-\left(y_{0}\right)^{p} \geq 0,\left(y_{0}\right)^{r}-\left(y_{0}\right)^{q} \geq 0,\left(y_{0}\right)^{p} \geq 0, \\
& \left(t_{0}\right)^{q}-\left(t_{0}\right)^{p} \geq 0,\left(t_{0}\right)^{r}-\left(t_{0}\right)^{q} \geq 0,\left(t_{0}\right)^{p} \geq 0,
\end{aligned}
$$

Step 3: Based of the Definition 2.6 the model (5) is changed over to a new model with three crisp objective functions. Now the model may be written as:

$$
\begin{aligned}
& \operatorname{Max}\left(c_{0}^{t} y_{0}+q_{0} t_{0}\right)^{p} \\
& \operatorname{Max}\left(c_{0}^{t} y_{0}+q_{0} t_{0}\right)^{p}-\left(c_{0}^{t} y_{0}+q_{0} t_{0}\right)^{q} \\
& \operatorname{Max}\left(c_{0}^{t} y_{0}+q_{0} t_{0}\right)^{p}+\left(c_{0}^{t} y_{0}+q_{0} t_{0}\right)^{r} \\
& \text { S.t } \\
& \left(a_{0} y_{0}\right)^{p}-\left(b_{0} t_{0}\right)^{r} \leq 0, \\
& \left(a_{0} y_{0}\right)^{p}-\left(b_{0} t_{0}\right)^{r}-\left(\left(a_{0} y_{0}\right)^{q}-\left(b_{0} t_{0}\right)^{q}\right) \leq 0, \\
& \left(a_{0} y_{0}\right)^{p}-\left(b_{0} t_{0}\right)^{r}+\left(\left(a_{0} y_{0}\right)^{r}-\left(b_{0} t_{0}\right)^{p}\right) \leq 0,
\end{aligned}
$$


$\left(d_{0}^{t} y_{0}+r_{0}\right)^{p}+t_{0}^{p} \leq 1$,

$\left(d_{0}^{t} y_{0}+r_{0}\right)^{p}+t_{0}^{p}-\left(d_{0}^{t} y_{0}+r_{0}\right)^{q}+t_{0}^{q} \leq 0$,

$\left(d_{0}^{t} y_{0}+r_{0}\right)^{p}+t_{0}^{p}+\left(d_{0}^{t} y_{0}+r_{0}\right)^{r}+t_{0}^{r} \leq 2$,

$\left(y_{0}\right)^{q}-\left(y_{0}\right)^{p} \geq 0,\left(y_{0}\right)^{r}-\left(y_{0}\right)^{q} \geq 0,\left(y_{0}\right)^{p} \geq 0$,

$\left(t_{0}\right)^{q}-\left(t_{0}\right)^{p} \geq 0,\left(t_{0}\right)^{r}-\left(t_{0}\right)^{q} \geq 0,\left(t_{0}\right)^{p} \geq 0$,

Step 4: Now using the lexicographic method in objective functions, we will get the result of the model (6). Therefore, we can write:

$\operatorname{Max}\left(c_{0}^{t} y_{0}+q_{0} t_{0}\right)^{p}$

S.t.

$\left(a_{0} y_{0}\right)^{p}-\left(b_{0} t_{0}\right)^{r} \leq 0$

$\left(a_{0} y_{0}\right)^{p}-\left(b_{0} t_{0}\right)^{r}-\left(\left(a_{0} y_{0}\right)^{q}-\left(b_{0} t_{0}\right)^{q}\right) \leq 0$,

$\left(a_{0} y_{0}\right)^{p}-\left(b_{0} t_{0}\right)^{r}+\left(\left(a_{0} y_{0}\right)^{r}-\left(b_{0} t_{0}\right)^{p}\right) \leq 0$,

$\left(d_{0}^{t} y_{0}+r_{0}\right)^{p}+t_{0}^{p} \leq 1$,

$\left(d_{0}^{t} y_{0}+r_{0}\right)^{p}+t_{0}^{p}-\left(d_{0}^{t} y_{0}+r_{0}\right)^{q}+t_{0}^{q} \leq 0$,

$\left(d_{0}^{t} y_{0}+r_{0}\right)^{p}+t_{0}^{p}+\left(d_{0}^{t} y_{0}+r_{0}\right)^{r}+t_{0}^{r} \leq 2$,

$\left(y_{0}\right)^{q}-\left(y_{0}\right)^{p} \geq 0,\left(y_{0}\right)^{r}-\left(y_{0}\right)^{q} \geq 0,\left(y_{0}\right)^{p} \geq 0$,

$\left(t_{0}\right)^{q}-\left(t_{0}\right)^{p} \geq 0,\left(t_{0}\right)^{r}-\left(t_{0}\right)^{q} \geq 0,\left(t_{0}\right)^{p} \geq 0$,

On the off chance that we get a special ideal arrangement, at that point it is an ideal arrangement of the issue (3) and stop. In any case go to following stage.

Step 5: Solve the accompanying issue over the ideal arrangements that are accomplished in Step 4 as follows:

$\operatorname{Max}\left(c_{0}^{t} y_{0}+q_{0} t_{0}\right)^{p}-\left(c_{0}^{t} y_{0}+q_{0} t_{0}\right)^{q}$

S.t.

$\left(c_{0}^{t} y_{0}+q_{0} t_{0}\right)^{p}=l^{*}$

$\left(a_{0} y_{0}\right)^{p}-\left(b_{0} t_{0}\right)^{r} \leq 0$,

$\left(a_{0} y_{0}\right)^{p}-\left(b_{0} t_{0}\right)^{r}-\left(\left(a_{0} y_{0}\right)^{q}-\left(b_{0} t_{0}\right)^{q}\right) \leq 0$,

$\left(a_{0} y_{0}\right)^{p}-\left(b_{0} t_{0}\right)^{r}+\left(\left(a_{0} y_{0}\right)^{r}-\left(b_{0} t_{0}\right)^{p}\right) \leq 0$,

$\left(d_{0}^{t} y_{0}+r_{0}\right)^{p}+t_{0}^{p} \leq 1$,

$\left(d_{0}^{t} y_{0}+r_{0}\right)^{p}+t_{0}^{p}-\left(d_{0}^{t} y_{0}+r_{0}\right)^{q}+t_{0}^{q} \leq 0$,

$\left(d_{0}^{t} y_{0}+r_{0}\right)^{p}+t_{0}^{p}+\left(d_{0}^{t} y_{0}+r_{0}\right)^{r}+t_{0}^{r} \leq 2$,

$\left(y_{0}\right)^{q}-\left(y_{0}\right)^{p} \geq 0$,

$\left(y_{0}\right)^{r}-\left(y_{0}\right)^{q} \geq 0$,

$\left(y_{0}\right)^{p} \geq 0$,

$\left(t_{0}\right)^{q}-\left(t_{0}\right)^{p} \geq 0$,

$\left(t_{0}\right)^{r}-\left(t_{0}\right)^{q} \geq 0$

$\left(t_{0}\right)^{p} \geq 0$,

where $l^{*}$ is the ideal estimation of issue (7). On the off chance that the issue (7) has a one of a kind ideal arrangement, at that point it is an ideal arrangement of issue (3) and stop. In any case go to following stage.
Step 6: Solve the accompanying issue over the ideal arrangements that are accomplished in Step 5 as follows:

$\operatorname{Max}\left(c_{0}^{t} y_{0}+q_{0} t_{0}\right)^{p}+\left(c_{0}^{t} y_{0}+q_{0} t_{0}\right)^{r}$

S.t.

$\left(c_{0}^{t} y_{0}+q_{0} t_{0}\right)^{p}-\left(c_{0}^{t} y_{0}+q_{0} t_{0}\right)^{q}=k^{*}$

$\left(c_{0}^{t} y_{0}+q_{0} t_{0}\right)^{p}=l^{*}$

$\left(a_{0} y_{0}\right)^{p}-\left(b_{0} t_{0}\right)^{r} \leq 0$,

$\left(a_{0} y_{0}\right)^{p}-\left(b_{0} t_{0}\right)^{r}-\left(\left(a_{0} y_{0}\right)^{q}-\left(b_{0} t_{0}\right)^{q}\right) \leq 0$,

$\left(a_{0} y_{0}\right)^{p}-\left(b_{0} t_{0}\right)^{r}+\left(\left(a_{0} y_{0}\right)^{r}-\left(b_{0} t_{0}\right)^{p}\right) \leq 0$,

$\left(d_{0}^{t} y_{0}+r_{0}\right)^{p}+t_{0}^{p} \leq 1$,

$\left(d_{0}^{t} y_{0}+r_{0}\right)^{p}+t_{0}^{p}-\left(d_{0}^{t} y_{0}+r_{0}\right)^{q}+t_{0}^{q} \leq 0$,

$\left(d_{0}^{t} y_{0}+r_{0}\right)^{p}+t_{0}^{p}+\left(d_{0}^{t} y_{0}+r_{0}\right)^{r}+t_{0}^{r} \leq 2$,

$\left(y_{0}\right)^{q}-\left(y_{0}\right)^{p} \geq 0,\left(y_{0}\right)^{r}-\left(y_{0}\right)^{q} \geq 0,\left(y_{0}\right)^{p} \geq 0$,

$\left(t_{0}\right)^{q}-\left(t_{0}\right)^{p} \geq 0,\left(t_{0}\right)^{r}-\left(t_{0}\right)^{q} \geq 0,\left(t_{0}\right)^{p} \geq 0$,

where $k^{*}$ is the ideal estimation of issue (8).Hence, the ideal arrangement of the issue (3) is gotten by taking care of issues (9).

Presently by hypothesis we explain the lexicographic ideal arrangement of the issue (7) can be considered as a definite ideal arrangement of the issue (3).

Theorem 3.2 If $\tilde{y}_{0}^{*}=\left(y_{0}^{*}\right)^{p},\left(y_{0}^{*}\right)^{q},\left(y_{0}^{*}\right)^{r}$ be an optimal solution of issues (7)-(8), at that point it is likewise a definite optimal solution of the issue (8).

Proof By the technique of inconsistency, let $\tilde{y}_{0}^{*}=\left(y_{0}^{*}\right)^{p}$, $\left(y_{0}^{*}\right)^{q},\left(y_{0}^{*}\right)^{r}$ be an optimal solution of (7)-(8), however, it is not the specific optimal solution of the issue (3). Here, we take up $\tilde{y}_{l}^{0}=\left(y_{l}^{0}\right)^{p},\left(y_{l}^{0}\right)^{q},\left(y_{l}^{0}\right)^{r}$, at the point of maximization:

$\left(c_{0}^{t} y_{0}^{*}\right)^{p},\left(c_{0}^{t} y_{0}^{*}\right)^{q},\left(c_{0}^{t} y_{0}^{*}\right)^{r} \prec\left(c_{0}^{t} y_{l}^{0}\right)^{p},\left(c_{0}^{t} y_{l}^{0}\right)^{q},\left(c_{0}^{t} y_{l}^{0}\right)^{r}$.

In light of definition (2.7), there are three conditions as follows:

Case(i) In the event of maximization, we take $\left(c_{0}^{t} y_{0}^{*}\right)^{p} \prec$ $\left(c_{0}^{t} y_{l}^{0}\right)^{p}$. Also, regarding with presumption we have:

$\left(A y_{l}^{0}\right)^{p}=\left(b_{0}\right)^{p}$,

$\left(A y_{l}^{0}\right)^{p}-\left(A y_{l}^{0}\right)^{q}=\left(b_{0}\right)^{p}-\left(b_{0}\right)^{q}$,

$\left(A y_{l}^{0}\right)^{p}+\left(A y_{l}^{0}\right)^{r}=\left(b_{0}\right)^{p}+\left(b_{0}\right)^{r}$,

$\left(y_{l}^{0}\right)^{p}-\left(y_{l}^{0}\right)^{q} \geq 0, \quad\left(y_{l}^{0}\right)^{r}-\left(y_{l}^{0}\right)^{q} \geq 0, \quad\left(y_{l}^{0}\right)^{p} \geq 0$.

In this manner, $\left(y_{l}^{0}\right)^{p},\left(y_{l}^{0}\right)^{q},\left(y_{l}^{0}\right)^{r}$ is a feasible solution of issue (7) in which the objective value in $\left(y_{l}^{0}\right)^{p},\left(y_{l}^{0}\right)^{q},\left(y_{l}^{0}\right)^{r}$ 
is greater than the objective value in $\left(y_{0}^{*}\right)^{p}, \quad\left(y_{0}^{*}\right)^{q}, \quad\left(y_{0}^{*}\right)^{r}$. However, it is logical inconsistency.

Case(ii) In the event of maximization, we take $\left(c_{0}^{t} y_{0}^{*}\right)^{p}=$ $\left(c_{0}^{t} y_{l}^{0}\right)^{p}$. and $\left(c_{0}^{t} y_{0}^{*}\right)^{p}-\left(c_{0}^{t} y_{0}^{*}\right)^{q} \succ\left(c_{0}^{t} y_{l}^{0}\right)^{p}-\left(c_{0}^{t} y_{l}^{0}\right)^{q}$ furthermore, regarding the suspicion we have:

$\left(A y_{l}^{0}\right)^{p}=\left(b_{0}\right)^{p}$,

$\left(A y_{l}^{0}\right)^{p}-\left(A y_{l}^{0}\right)^{q}=\left(b_{0}\right)^{p}-\left(b_{0}\right)^{q}$,

$\left(A y_{l}^{0}\right)^{p}+\left(A y_{l}^{0}\right)^{r}=\left(b_{0}\right)^{p}+\left(b_{0}\right)^{r}$,

$\left(y_{l}^{0}\right)^{p}-\left(y_{l}^{0}\right)^{q} \geq 0, \quad\left(y_{l}^{0}\right)^{r}-\left(y_{l}^{0}\right)^{q} \geq 0, \quad\left(y_{l}^{0}\right)^{p} \geq 0$.

Therefore, $\left(y_{l}^{0}\right)^{p},\left(y_{l}^{0}\right)^{q},\left(y_{l}^{0}\right)^{r}$ is a feasible solution of issue (3) in which the objective value in $\left(y_{l}^{0}\right)^{p},\left(y_{l}^{0}\right)^{q}$, $\left(y_{l}^{0}\right)^{r}$ is greater than the objective value in $\left(y_{0}^{*}\right)^{p}, \quad\left(y_{0}^{*}\right)^{q}$, $\left(y_{0}^{*}\right)^{r}$.However, it is logical inconsistency.

Case(iii) In the event of maximization, we take up $\left(c_{0}^{t} y_{0}^{*}\right)^{p}=$ $\left(c_{0}^{t} y_{l}^{0}\right)^{p} .\left(c_{0}^{t} y_{0}^{*}\right)^{p}-\left(c_{0}^{t} y_{0}^{*}\right)^{q}=\left(c_{0}^{t} y_{l}^{0}\right)^{p}-\left(c_{0}^{t} y_{l}^{0}\right)^{q}$ and $\left(c_{0}^{t} y_{0}^{*}\right)^{p}+\left(c_{0}^{t} y_{0}^{*}\right)^{r}<\left(c_{0}^{t} y_{l}^{0}\right)^{p}+\left(c_{0}^{t} y_{l}^{0}\right)^{r}$. Furthermore, regarding the suspicion we have:

$\left(A y_{l}^{0}\right)^{p}=\left(b_{0}\right)^{p}$,

$\left(A y_{l}^{0}\right)^{p}-\left(A y_{l}^{0}\right)^{q}=\left(b_{0}\right)^{p}-\left(b_{0}\right)^{q}$,

$\left(A y_{l}^{0}\right)^{p}+\left(A y_{l}^{0}\right)^{r}=\left(b_{0}\right)^{p}+\left(b_{0}\right)^{r}$,

$\left(y_{l}^{0}\right)^{p}-\left(y_{l}^{0}\right)^{q} \geq 0, \quad\left(y_{l}^{0}\right)^{r}-\left(y_{l}^{0}\right)^{q} \geq 0, \quad\left(y_{l}^{0}\right)^{p} \geq 0$.

Long these lines, $\left(y_{l}^{0}\right)^{p},\left(y_{l}^{0}\right)^{q},\left(y_{l}^{0}\right)^{r}$ is a feasible solution of issue (8) in which the objective value in $\left(y_{l}^{0}\right)^{p},\left(y_{l}^{0}\right)^{q}$, $\left(y_{l}^{0}\right)^{r}$ is greater than the objective value in $\left(y_{0}^{*}\right)^{p}, \quad\left(y_{0}^{*}\right)^{q}$, $\left(y_{0}^{*}\right)^{r}$. However, it is logical inconsistency.

In this manner $\tilde{y}_{0}^{*}=\left(y_{0}^{*}\right)^{p},\left(y_{0}^{*}\right)^{q},\left(y_{0}^{*}\right)^{r}$ is an exact optimal solution of issue (3).

\section{Shortcomings and limitations of Das et al.'s method}

There are a few techniques in writing that can be utilized to take care of FFLP issues by using lexicographic technique, ranking criteria, membership function and yield arrangements with remarkable ideal fuzzy qualities. Be that as it may, those techniques must be utilized to locate the extraordinary objective fuzzy solution of FFLP issues with inequality constraints. In this segment, we remark on the deficiencies and impediments of some current strategies for taking care of FFLFP issues, including those utilizing lexicographic positioning rules. The current lexicographic technique (Hashemi et al. 2006) can't be utilized to take care of FFLP issues in which the boundaries and choice factors are subjective L$\mathrm{R}$ fuzzy numbers. The ranking functions utilized with the current strategies $[15,18]$ ) do not have the all-out request properties; thus, these techniques cannot be utilized to locate the unique optimal fuzzy estimation of FFLFP issues. To take care of FFLFP issues by utilizing the enrollment capacity of Veeramani and Sumathi [22,24], there is a need to rough all the difficult boundaries and limitations to their relating triangular fuzzy numbers. Along these lines, got arrangements are estimated and don't fulfill the issue requirements precisely. The current technique [25] utilizes Pareto ideal arrangement and the boundaries are taken just fuzzy triangular numbers to take care of FFLFP issues. Nonetheless, the Pareto ideal arrangement calculation doesn't ensure to fulfill the issue precisely. Besides, their strategy can't be used to locate the unique optimal fuzzy estimation of the FFLFP issues [23] proposed a procedure for taking care of FFLFP issues without changing them into old style fresh issues. Their procedure utilizes parametric strategy on trapezoidal fuzzy numbers.

In outline, as far as we could possibly know, the current techniques $[2,15,16,18,22-25]$ cannot be utilized to locate the one of a kind unique fuzzy optimal solution of the FFLFP issue with non-negative triangular fuzzy numbers. In the above existing strategies, they have taken different technique for taking care of FLFP issue. Be that as it may, we consider just lexicographic requesting which was proposed by the current technique [16]. Thus, we needn't bother with the above existing strategies $[2,15,16,18,22-25]$ to contrast and our proposed technique. Consequently, we just contrast the proposed technique and the current strategy [16]. Table 1 outlines a few highlights of the above referred to techniques for taking care of FFLP issues, and the commitment of the current investigation.

Das et al.'s method [16] has the accompanying weakness and impediments, which make it unsatisfactory for discovering arrangements of FIFLP problem (1) with remarkable optimal objective values:

- In general, the current technique proposed a strategy to tackle LFP issue with fuzzy number utilizing MOLFP issue in which the constraints and factors are triangular fuzzy numbers. Be that as it may, they have not taken nonnegative fuzzy number.

- Due to more constraints and factors, the computational multifaceted nature is high.

In the following segment, we propose a few changes to the technique for Das et al.'s. [16] to dispense with the previously mentioned inadequacies and confinements. 
Table 1 Features of some current strategies for taking care of FFLFP issues and commitment of the current examination

\begin{tabular}{llllc}
\hline Existing method & Fuzzy number & Criterion & Equality & Inequality \\
\hline Veeramani and Sumathi [22] & Triangular fuzzy number & Membership function & - & Yes \\
Veeramani and Sumathi [24] & Triangular fuzzy number & Zadeh extension principle & - & Yes \\
Stanojevic and Stanojevic [25] & Triangular fuzzy number & Pareto Optimal solution & - & Yes \\
Stanojevic and Stanojevic [23] & Triangular fuzzy number & Parametric method & - & Yes \\
Bogdana Pop and Stancu-minasian [2] & Triangular fuzzy number & Kerre's method & - & Yes \\
Das et al. [15] & Triangular fully fuzzy number & Simple ranking method & Yes & Yes \\
Das et al. [16] & Triangular fully fuzzy number & Lexicographic ordering & - & Yes \\
Das et al. [18] & Triangular fuzzy number & Ranking function & Yes & Yes \\
Present study & Triangular fully fuzzy number & Lexicographic ordering & Yes & Yes \\
\hline
\end{tabular}

\section{Proposed approach}

In light of the past section, we are prepared to adjusted their technique and consider that the loose information are nonnegative triangular fuzzy numbers. In this segment, we examined about the computational multifaceted nature of an issue. The computational intricacy of LFP issue is straightforwardly corresponding to the quantity of its limitations and factors. The upside of calculation multifaceted nature is lessening the imperatives and factors of issue LFP models. We chiefly center that the ideal arrangements are nonnegative triangular fuzzy numbers.

Let us consider an overall arrangement of FFLFP issue as follows:

$$
\operatorname{Max}(\operatorname{Min}) \tilde{Z}_{0}=\frac{\tilde{c}_{0}^{t} \tilde{x}_{0}+\tilde{q}_{0}}{\tilde{d}_{0}^{t} \tilde{x}_{0}+\tilde{r}_{0}}
$$

S.t.

$\tilde{A}_{0} \tilde{x}_{0} \leq \tilde{b}_{0}$

$\tilde{x}_{0} \geq 0$.

Let us expect that all the boundaries $\tilde{x}_{0}, \tilde{c}_{0}, \tilde{q}_{0}, \tilde{d}_{0}, \tilde{r}_{0}, \tilde{b}_{0}$ and $\tilde{z}_{0}$ are taken by nonnegative triangular fuzzy numbers $\left(\left(x_{0}\right)^{p}, \quad\left(x_{0}\right)^{q}, \quad\left(x_{0}\right)^{r}\right),\left(\left(c_{0}^{t}\right)^{p}, \quad\left(c_{0}^{t}\right)^{q}, \quad\left(c_{0}^{t}\right)^{r}\right),\left(\left(q_{0}\right)^{p}, \quad\left(q_{0}\right)^{q}\right.$, $\left.\left(q_{0}\right)^{r}\right),\left(\left(d_{0}^{t}\right)^{p}, \quad\left(d_{0}^{t}\right)^{q}, \quad\left(d_{0}^{t}\right)^{r}\right),\left(\left(b_{0}\right)^{p},\left(b_{0}\right)^{q},\left(b_{0}\right)^{r}\right),\left(\left(r_{0}\right)^{p}\right.$, $\left.\left(r_{0}\right)^{q},\left(r_{0}\right)^{r}\right)$ and $\left(\left(a_{0}\right)^{p},\left(a_{0}\right)^{q},\left(a_{0}\right)^{r}\right)$, respectively. In the wake up figuring the fuzzy quantities concerning definitions 2.2 and 2.3 we change the expansion the objective function and constraints function depicted by a nonnegative triangular fuzzy number with the maximization of three values of the fuzzy number. At that point we can change the referenced FFLFP issue as follows:

$$
\begin{aligned}
& \operatorname{Max}\left(z_{1}, z_{2}, z_{3}\right) \\
& =\frac{\left(\left(c_{0}^{t} x_{0}\right)^{p},\left(c_{0}^{t} x_{0}\right)^{q},\left(c_{0}^{t} x_{0}\right)^{r}\right)+\left(\left(q_{0}\right)^{p},\left(q_{0}\right)^{q},\left(q_{0}\right)^{r}\right)}{\left(\left(d_{0}^{t} x_{0}\right)^{p},\left(d_{0}^{t} x_{0}\right)^{q},\left(d_{0}^{t} x_{0}\right)^{r}\right)+\left(\left(r_{0}\right)^{p},\left(r_{0}\right)^{q},\left(r_{0}\right)^{r}\right)}
\end{aligned}
$$

S.t.

$\left(\left(a_{0}\right)^{p},\left(a_{0}\right)^{q},\left(a_{0}\right)^{r}\right) \otimes\left(\left(x_{0}\right)^{p},\left(x_{0}\right)^{q},\left(x_{0}\right)^{r}\right) \leq\left(\left(b_{0}\right)^{p},\left(b_{0}\right)^{q},\left(b_{0}\right)^{r}\right)$, $\left(\left(x_{0}\right)^{p},\left(x_{0}\right)^{q},\left(x_{0}\right)^{r}\right) \geq 0$.

The proposed technique for understanding FFLFPP can be summed up as follows:

Step 1: With regard to Definition 2.4 the issue (11), can be changed as:

$\operatorname{Max} \frac{\left(\left(c_{0}^{t} x_{0}+q_{0}\right)^{p}\right.}{\left(\left(d_{0}^{t} x_{0}+r_{0}\right)^{p}\right.}, \frac{\left(\left(c_{0}^{t} x_{0}+q_{0}\right)^{q}\right.}{\left(\left(d_{0}^{t} x_{0}+r_{0}\right)^{q}\right.}, \frac{\left(\left(c_{0}^{t} x_{0}+q_{0}\right)^{r}\right.}{\left(\left(d_{0}^{t} x_{0}+r_{0}\right)^{r}\right.}$

S.t.

$\left(a_{0} x_{0}\right)^{p} \leq\left(b_{0}\right)^{p},\left(a_{0} y_{0}\right)^{q} \leq\left(b_{0}\right)^{q},\left(a_{0} y_{0}\right)^{r} \leq\left(b_{0}\right)^{r}$,

$\left(x_{0}\right)^{q}-\left(x_{0}\right)^{p} \geq 0,\left(x_{0}\right)^{r}-\left(x_{0}\right)^{q} \geq 0,\left(x_{0}\right)^{p} \geq 0$,

Step 2: As to 2.6 the issue (12) is changed over to the MOLFP issue with three objective functions as follows:

$\operatorname{Max}(\operatorname{Min}) \frac{\left(c_{0}^{t} x_{0}+q_{0}\right)^{q}}{\left(d_{0}^{t} x_{0}+r_{0}\right)^{q}}$

$\operatorname{Min}(\operatorname{Max}) \frac{\left(c_{0}^{t} x_{0}+q_{0}\right)^{r}}{\left(d_{0}^{t} x_{0}+r_{0}\right)^{r}}-\frac{\left(c_{0}^{t} x_{0}+q_{0}\right)^{p}}{\left(d_{0}^{t} x_{0}+r_{0}\right)^{p}}$,

$\operatorname{Max}(\operatorname{Min}) \frac{\left(c_{0}^{t} x_{0}+q_{0}\right)^{p}}{\left(d_{0}^{t} x_{0}+r_{0}\right)^{p}}+\frac{\left(c_{0}^{t} x_{0}+q_{0}\right)^{r}}{\left(d_{0}^{t} x_{0}+r_{0}\right)^{r}}$,

S.t

$\left(a_{0} x_{0}\right)^{p} \leq\left(b_{0}\right)^{p}$

$\left(a_{0} y_{0}\right)^{q} \leq\left(b_{0}\right)^{q}$,

$\left(a_{0} y_{0}\right)^{r} \leq\left(b_{0}\right)^{r}$,

$\left(x_{0}\right)^{q}-\left(x_{0}\right)^{p} \geq 0,\left(x_{0}\right)^{r}-\left(x_{0}\right)^{q} \geq 0,\left(x_{0}\right)^{p} \geq 0$,

$\left(a_{0} x_{0}\right)^{p} \leq\left(b_{0}\right)^{p},\left(a_{0} y_{0}\right)^{q} \leq\left(b_{0}\right)^{q},\left(a_{0} y_{0}\right)^{r} \leq\left(b_{0}\right)^{r}$,

$\left(x_{0}\right)^{q}-\left(x_{0}\right)^{p} \geq 0,\left(x_{0}\right)^{r}-\left(x_{0}\right)^{q} \geq 0,\left(x_{0}\right)^{p} \geq 0$,

Step 3: In objective functions the lexicographic method will be utilized to acquire the optimal solution of the issue (13). Thus, we obtain:

$\operatorname{Max}(\operatorname{Min}) \frac{\left(c_{0}^{t} x_{0}+q_{0}\right)^{q}}{\left(d_{0}^{t} x_{0}+r_{0}\right)^{q}}$, 
S.t.

$\left(a_{0} x_{0}\right)^{p} \leq\left(b_{0}\right)^{p}$,

$\left(a_{0} y_{0}\right)^{q} \leq\left(b_{0}\right)^{q}$,

$\left(a_{0} y_{0}\right)^{r} \leq\left(b_{0}\right)^{r}$,

$\left(x_{0}\right)^{q}-\left(x_{0}\right)^{p} \geq 0,\left(x_{0}\right)^{r}-\left(x_{0}\right)^{q} \geq 0,\left(x_{0}\right)^{p} \geq 0$,

In the event that we get an exceptional optimal solution, at that point it is an optimal solution of the issue (11) and stop. In any case go the following stage.

Step 4: Solve the accompanying issue to the ideal solutions that are accomplished in Step 4 as follows:

$\operatorname{Min}(\operatorname{Max}) \frac{\left(c_{0}^{t} x_{0}+q_{0}\right)^{r}}{\left(d_{0}^{t} x_{0}+r_{0}\right)^{r}}-\frac{\left(c_{0}^{t} x_{0}+q_{0}\right)^{p}}{\left(d_{0}^{t} x_{0}+r_{0}\right)^{p}}$,

S.t.

$\frac{\left(c_{0}^{t} x_{0}+q_{0}\right)^{q}}{\left(d_{0}^{t} x_{0}+r_{0}\right)^{q}}=l^{*}$

$\left(a_{0} x_{0}\right)^{p} \leq\left(b_{0}\right)^{p}$

$\left(a_{0} y_{0}\right)^{q} \leq\left(b_{0}\right)^{q}$,

$\left(a_{0} y_{0}\right)^{r} \leq\left(b_{0}\right)^{r}$,

$\left(x_{0}\right)^{q}-\left(x_{0}\right)^{p} \geq 0,\left(x_{0}\right)^{r}-\left(x_{0}\right)^{q} \geq 0,\left(x_{0}\right)^{p} \geq 0$,

where $l^{*}$ is the ideal solution of issue (14). On the off chance that the issue (14) has a remarkable ideal solution, at that point it is an ideal solution of issue (11) and stop. In any case go to following stage.

Step 5: Solve the accompanying issue to the ideal arrangements that are accomplished in Step 4 as follows:

$\operatorname{Max}(\operatorname{Min}) \frac{\left(c_{0}^{t} x_{0}+q_{0}\right)^{p}}{\left(d_{0}^{t} x_{0}+r_{0}\right)^{p}}+\frac{\left(c_{0}^{t} x_{0}+q_{0}\right)^{r}}{\left(d_{0}^{t} x_{0}+r_{0}\right)^{r}}$,

S.t.

$\frac{\left(c_{0}^{t} x_{0}+q_{0}\right)^{r}}{\left(d_{0}^{t} x_{0}+r_{0}\right)^{r}}-\frac{\left(c_{0}^{t} x_{0}+q_{0}\right)^{p}}{\left(d_{0}^{t} x_{0}+r_{0}\right)^{p}}=k^{*}$.

$\frac{\left(c_{0}^{t} x_{0}+q_{0}\right)^{q}}{\left(d_{0}^{t} x_{0}+r_{0}\right)^{q}}=l^{*}$

$\left(a_{0} x_{0}\right)^{p} \leq\left(b_{0}\right)^{p}$,

$\left(a_{0} y_{0}\right)^{q} \leq\left(b_{0}\right)^{q}$

$\left(a_{0} y_{0}\right)^{r} \leq\left(b_{0}\right)^{r}$,

$\left(x_{0}\right)^{q}-\left(x_{0}\right)^{p} \geq 0,\left(x_{0}\right)^{r}-\left(x_{0}\right)^{q} \geq 0,\left(x_{0}\right)^{p} \geq 0$,

where $k^{*}$ is the optimal value of issue (15). Hence, the optimal solution of the issue (11) is acquired by taking care of issues (16).

\section{Main results}

In this section, here we solve a new problem which is equivalent to the problem (14). We just guarantee that the optimal solutions are nonnegative triangular fuzzy numbers. Along these lines, we take care of the accompanying issue rather than issue (14):

$\operatorname{Max}(\operatorname{Min}) \frac{\left(c_{0}^{t} x_{0}+q_{0}\right)^{q}}{\left(d_{0}^{t} x_{0}+r_{0}\right)^{q}}$,

S.t.

$\left(a_{0} x_{0}\right)^{q} \leq\left(b_{0}\right)^{q}$

$\left(x_{0}\right)^{q} \geq 0$,

We change the Problem (17) in to a crisp LP issue by utilizing Charnes-Cooper change [1], and acquire the accompanying issue:

$\operatorname{Max}\left(c_{0}^{t} y_{0}+q_{0} t_{0}\right)^{q}$

Subject to

$\left(a_{0} y_{0}\right)^{q}-\left(b_{0} t_{0}\right)^{q} \leq 0$,

$\left(d_{0} y_{0}+r_{0} t_{0}\right)^{q} \leq 1$,

$\left(y_{0}\right)^{q}, t_{0} \geq 0$.

In the objective function of issue (15) includes the constraints $\left(x_{0}\right)^{p}$ and $\left(x_{0}\right)^{r}$. Along these lines, the constraints which are regarding of $(x)^{q}$ are jobless and a long way from the feasible solutions of issue (15). Thusly, we tackle the accompanying issue rather than issue (15):

$\operatorname{Min}(\operatorname{Max}) \frac{\left(c_{0}^{t} x_{0}+q_{0}\right)^{r}}{\left(d_{0}^{t} x_{0}+r_{0}\right)^{r}}-\frac{\left(c_{0}^{t} x_{0}+q_{0}\right)^{p}}{\left(d_{0}^{t} x_{0}+r_{0}\right)^{p}}$,

S.t.

$\left(a_{0} x_{0}\right)^{p} \leq\left(b_{0}\right)^{p}$,

$\left(a_{0} x_{0}\right)^{r} \leq\left(b_{0}\right)^{r}$,

$\left(x_{0}\right)^{p} \leq\left(x_{0}^{*}\right)^{q}$,

$\left(x_{0}\right)^{r} \geq\left(x_{0}^{*}\right)^{q}$,

$\left(x_{0}\right)^{p} \geq 0$,

Here $\left(\tilde{x}_{0}^{*}\right)^{q}=\left(\left(\tilde{x}_{1}^{*}\right)^{q},\left(\tilde{x}_{2}^{*}\right)^{q},\left(\tilde{x}_{3}^{*}\right)^{q}\right)$ has an optimal solution.

In the above problem (19), there are two types of constraints involved namely $(x)^{p}$ and $(x)^{r}$. Therefore, the problem is decomposed into the following two LFP problems as follows:

$\operatorname{Max}(\operatorname{Min}) \frac{\left(c_{0}^{t} x_{0}+q_{0}\right)^{p}}{\left(d_{0}^{t} x_{0}+r_{0}\right)^{p}}$

S.t.

$\left(a_{0} x_{0}\right)^{p} \leq\left(b_{0}\right)^{p}$

$0 \leq\left(x_{0}\right)^{p} \leq\left(x_{0}^{*}\right)^{q}$. 
With the assistance of Charnes-Cooper [1] technique, we changed the issue (20) into crisp LP issue and the model can be written as:

$\operatorname{Max}\left(c_{0}^{t} y_{0}+q_{0} t_{0}\right)^{p}$

Subject to

$\left(a_{0} y_{0}\right)^{p}-\left(b_{0} t_{0}\right)^{p} \leq 0$,

$\left(d_{0} y_{0}+r_{0} t_{0}\right)^{p} \leq 1$,

$0 \leq\left(y_{0}\right)^{p} \leq\left(y_{0}^{*}\right)^{q}, t_{0} \geq 0$,

$\operatorname{Min}(\operatorname{Max}) \frac{\left(c_{0}^{t} x_{0}+q_{0}\right)^{r}}{\left(d_{0}^{t} x_{0}+r_{0}\right)^{r}}$

S.t.

$\left(a_{0} x_{0}\right)^{r} \leq\left(b_{0}\right)^{r}$,

$\left(x_{0}\right)^{r} \geq\left(x_{0}^{*}\right)^{q}$.

We changed the issue (22) in to a crisp LP issue by utilizing Charnes-Cooper change [1], and obtain the following problem.

$\operatorname{Max}\left(c_{0}^{t} y_{0}+q_{0} t_{0}\right)^{r}$

Subject to $\left(a_{0} y_{0}\right)^{r}-\left(b_{0} t_{0}\right)^{r} \leq 0$,

$\left(d_{0} y_{0}+r_{0} t_{0}\right)^{r} \leq 1$,

$0 \leq\left(y_{0}\right)^{r} \leq\left(y_{0}^{*}\right)^{q}, t_{0} \geq 0$.

In the event that both the issues (21) and (23) have a one of a kind of optimal solution as $\left(y_{0}^{*}\right)^{p}$ and $\left(y_{0}^{*}\right)^{r}$ respectively, at that point the ideal arrangement of issue (1) is $\tilde{y}_{0}^{*}=\left(\left(y_{0}^{*}\right)^{p}\right.$, $\left.\left(y_{0}^{*}\right)^{q},\left(y_{0}^{*}\right)^{r}\right)$ and stop.

In the wake of getting the above optimal solution, we put in the issue (1) and get the solution is $\tilde{x}_{0}^{*}=\left(\left(x_{0}^{*}\right)^{p},\left(x_{0}^{*}\right)^{q}\right.$, $\left.\left(x_{0}^{*}\right)^{r}\right)$.

\section{Computational discussion}

In this section, we compare the complexity of the LFP models derived by our proposed approach with those obtained by proposed method by Das et al. [16]. It is very well-known that the computational complexity of the problem depends directly on the number of the constraints and the variables of LFP problems. In what follows, we are going to compare the number of the constraints and variables of problem (7) and (14). Problem $(7)$ has $(6 m+5 n)$ constraints, while problem (14) has $(3 m+3 n)$ constraints. This shows that problem (7) has $(3 m+2 n)$ constraints more than problem (14). Also, the standard form of problem (7) has $5 n$ variables (considering slacks), while the standard form of problem (14) has $3 n$ variables (considering slacks). Thus, problem (7) has $2 n$ variables more than problem (14). Thus, utilizing problem (14) gives us a computational advantage compared to problem (7), regarding the number of constraints and variables. In a similar way, we compare the number of the constraints and variables of problems (8) with problems (15) or (16). Hence, regarding the above discussion utilizing problems (14), (15) and (16) is preferred to problems (7), (8), and (8) because of their computational advantages.

\section{Numerical model}

In this segment, we show the proposed strategy to solve FFLFP issue and afterward analyze the computational intricacy of the proposed technique with Das et al.'s strategy [16].

Example 5.1 [16]. Let us consider the accompanying LFP as follows:

$\operatorname{Max} z=\frac{x_{1}-x_{2}+1}{x_{1}+x_{2}+2}$

S.t.

$x_{1}+x_{2} \leq 2$

$x_{1}-x_{2} \leq 1$,

$x_{1}, x_{2} \geq 0$.

The optimal solution of the problem is $\mathrm{x}_{1}=1, \mathrm{x}_{2}=0$ and the optimal value of $\mathrm{z}$ is $2 / 3=0.66667$.

In this manner, the completely fuzzy LFP issue which we need to understand is as per the following:

$\operatorname{Max} z=\frac{(0,1,2) \tilde{x}_{1}-(-2,-1,0)_{2} \tilde{x}_{2}+(0,1,2)}{(0,1,2) \tilde{x}_{1}+(0,1,2) \tilde{x}_{2}+(1,2,3)}$

S.t.

$(1,2,3) \tilde{x}_{1}+(1,2,3) \tilde{x}_{2} \leq(1,2,3)$,

$(0,1,2) \tilde{x}_{1}-(-2,-1,0) \tilde{x}_{2} \leq(0,1,2)$,

$\tilde{x}_{1}, \tilde{x}_{2} \geq 0$.

Presently the issue is as per the following:

$\operatorname{Max} \frac{(0,1,2) \otimes\left(\left(x_{1}\right)^{p},\left(x_{1}\right)^{q},\left(x_{1}\right)^{r}\right)-(-2,-1,0) \otimes\left(\left(x_{2}\right)^{p},\left(x_{2}\right)^{q},\left(x_{2}\right)^{r}\right)+(0,1,2)}{(0,1,2) \otimes\left(\left(x_{1}\right)^{p},\left(x_{1}\right)^{q},\left(x_{1}\right)^{r}\right)+(0,1,2) \otimes\left(\left(x_{2}\right)^{p},\left(x_{2}\right)^{q},\left(x_{2}\right)^{r}\right)+(1,2,3)}$ S.t.

$(0,1,2) \otimes\left(\left(x_{1}\right)^{p},\left(x_{1}\right)^{q},\left(x_{1}\right)^{r}\right)+(0,1,2) \otimes\left(\left(x_{2}\right)^{p},\left(x_{2}\right)^{q},\left(x_{2}\right)^{r}\right) \leq(1,2,3)$,

$(0,1,2) \otimes\left(\left(x_{1}\right)^{p},\left(x_{1}\right)^{q},\left(x_{1}\right)^{r}\right)-(-2,-1,0) \otimes\left(\left(x_{2}\right)^{p},\left(x_{2}\right)^{q},\left(x_{2}\right)^{r}\right) \leq(0,1,2)$,

$\left(x_{1}\right)^{p},\left(x_{1}\right)^{q},\left(x_{1}\right)^{r},\left(x_{2}\right)^{p},\left(x_{2}\right)^{q},\left(x_{2}\right)^{r} \geq 0$. 
As indicated by Step 2, we get the accompanying numerous objective LFP issue as follows:

$\operatorname{Max}(\operatorname{Min}) \frac{1\left(x_{1}\right)^{q}-(-1)\left(x_{2}\right)^{q}+1}{1\left(x_{1}\right)^{q}+1\left(x_{2}\right)^{q}+2}$
$\operatorname{Max}(\operatorname{Min}) \frac{2\left(x_{1}\right)^{r}-0\left(x_{2}\right)^{r}+2}{2\left(x_{1}\right)^{r}+2\left(x_{2}\right)^{r}+3}-\frac{0\left(x_{1}\right)^{p}-(-2)\left(x_{2}\right)^{p}}{0\left(x_{1}\right)^{p}+0\left(x_{2}\right)^{p}+1}$
$\operatorname{Max}(\operatorname{Min}) \frac{0\left(x_{1}\right)^{p}-(-2)\left(x_{2}\right)^{p}}{0\left(x_{1}\right)^{p}+0\left(x_{2}\right)^{p}+1}+\frac{2\left(x_{1}\right)^{r}-0\left(x_{2}\right)^{r}+2}{2\left(x_{1}\right)^{r}+2\left(x_{2}\right)^{r}+3}$

S.t.

$0\left(x_{1}\right)^{p}+0\left(x_{2}\right)^{p} \leq 1$,

$2\left(x_{2}\right)^{p} \leq 0$,

$\left(x_{1}\right)^{q}+\left(x_{2}\right)^{q} \leq 2$,

$\left(x_{1}\right)^{q}-(-1)\left(x_{2}\right)^{q} \leq 1$,

$2\left(x_{1}\right)^{r}+2\left(x_{2}\right)^{r} \leq 3$,

$2\left(x_{1}\right)^{r} \leq 2$

$\left(x_{j}\right)^{q}-\left(x_{j}\right)^{p} \geq 0, j=1,2$,

$\left(x_{j}\right)^{r}-\left(x_{j}\right)^{q} \geq 0, j=1,2$,

$\left(x_{j}\right)^{p} \geq 0, \quad j=1,2$,

With respect to (20) we initially tackle the accompanying issue:

$\operatorname{Max}(\operatorname{Min}) \frac{1\left(x_{1}\right)^{q}-(-1)\left(x_{2}\right)^{q}+1}{1\left(x_{1}\right)^{q}+1\left(x_{2}\right)^{q}+2}$

S.t

$\left(x_{1}\right)^{q}+\left(x_{2}\right)^{q} \leq 2$,

$\left(x_{1}\right)^{q}-(-1)\left(x_{2}\right)^{q} \leq 1$,

$\left(x_{j}\right)^{q} \geq 0, j=1,2$,

The issue (27) is a crisp LFP issue, which can be changed over into a crisp LP issue by utilizing Chranes-Cooper [1] strategy. The changed LP issues are illuminated by old style strategies.

The optimal solution of issue (27) is gotten as $\left(\left(x_{1}^{*}\right)^{q},\left(x_{2}^{*}\right)^{q}\right)=(1,0)$.

In the above issue we see that the adjusted technique is exceptionally less factors and less limitations when contrasted with the current strategy Das et al.'s strategy. Be that as it may, the current technique Das et al.'s strategy [16] contains nine limitations and six factors; however, in our concern (27) contains just two requirements and two factors.

In the subsequent stage, we utilizing the optimal solution of issue (27) and the issue (20) and (21), the accompanying issues are fathomed as follows:

$$
\begin{aligned}
& \operatorname{Max} \frac{0\left(x_{1}\right)^{p}-(-2)\left(x_{2}\right)^{p}}{0\left(x_{1}\right)^{p}+0\left(x_{2}\right)^{p}+1} \text { S.t } \\
& 0\left(x_{1}\right)^{p}+0\left(x_{2}\right)^{p} \leq 1,
\end{aligned}
$$

$2\left(x_{2}\right)^{p} \leq 0$,

$$
\left(x_{1}\right)^{p} \leq 1, \quad\left(x_{2}\right)^{p} \leq 0,
$$$$
\left(x_{1}\right)^{p},\left(x_{2}\right)^{p} \geq 0 \text {, }
$$

The issue (28) is a crisp LFP issue, which can be changed over into a crisp LP issue by utilizing Chranes-Cooper [1] technique. The changed LP issues are fathomed by old style techniques.

$\operatorname{Min} \frac{2\left(x_{1}\right)^{r}-0\left(x_{2}\right)^{r}+2}{2\left(x_{1}\right)^{r}+2\left(x_{2}\right)^{r}+3}$

S.t.

$2\left(x_{1}\right)^{r}+2\left(x_{2}\right)^{r} \leq 3$

$2\left(x_{1}\right)^{r} \leq 2$

$\left(x_{1}\right)^{r} \geq 0, \quad\left(x_{2}\right)^{r} \geq 3$,

The issue (29) is a crisp LFP issue, which can be changed over into a crisp LP issue by utilizing Chranes-Cooper [1] technique. The changed LP issues are fathomed by old style techniques.

The optimal solutions of problem (28) and (29) are obtained as $\left(\left(x_{1}^{*}\right)^{p},\left(x_{2}^{*}\right)^{p}\right)=(0,0)$ and $\left(\left(x_{1}^{*}\right)^{r},\left(x_{2}^{*}\right)^{r}\right)=(1$, $0)$, respectively.

Since, the problem (27) and (29) get an unique optimal solutions and use the optimal solution of above problem we get the optimal solutions of problem (24) as follows and stop.

At that point the arrangement of the issue is:

$$
\begin{aligned}
& \tilde{x}^{*}=\left\{\tilde{x}_{1}^{*}=\left(\left(x_{1}^{*}\right)^{p},\left(x_{1}^{*}\right)^{q},\left(x_{1}^{*}\right)^{r}\right)=\left(\begin{array}{lll}
0, & 1, & 1
\end{array}\right),\right. \\
& \tilde{x}^{*}=\left\{\tilde{x}_{2}^{*}=\left(\left(x_{2}^{*}\right)^{p},\left(x_{2}^{*}\right)^{q},\left(x_{2}^{*}\right)^{r}\right)=\left(\begin{array}{lll}
0, & 0,0
\end{array}\right)\right. \text {, }
\end{aligned}
$$

The triangular fuzzy number $\tilde{z}^{*}=\left(\begin{array}{ll}0,0.66667,4 & 4\end{array}\right)$

The acquired outcome is actually the ideal solution of the difficulties which start with the first issue and accurate worth those depending on existing calculation proposed by Das et al.'s strategy [16]. In any case, by contrasting proposed strategy results and the existing technique $[15,16]$, it is a lot simpler, more proficient and computational multifaceted nature more productive.

\section{Case study}

In this section, a genuine issue given in $[15,16]$ is comprehended by the proposed technique and making an examination with other exploration of a similar model. In this segment, to show the utilization of proposed technique the genuine issue is tackled by the proposed strategy. 
Table 2 Supply of the plants

\begin{tabular}{llll}
\hline Source & Changhua & Touliu & Hsinchu \\
\hline Supply (thousand dozen bottles) & $(7.2,8,8.8)$ & $(12,14,16)$ & $(10.2,12,13.8)$ \\
\hline
\end{tabular}

Table 3 Demand of the destinations

\begin{tabular}{lllll}
\hline Destination & Taichung & Chiayi & Kaohsiung & Taipei \\
\hline Demand (thousand dozen bottles) & $(6.2,7,7.8)$ & $(8.9,10,11.1)$ & $(6.5,8,9.5)$ & $(7.8,9,10.2)$ \\
\hline
\end{tabular}

Table 4 Profit of the company

\begin{tabular}{lllll}
\hline Source & Destination & & \\
\cline { 2 - 5 } & Taichung & Chiayi & Kaohsiung & Taipei \\
\hline Changhua & $(8,10,10.8)$ & $(20.4,22,24)$ & $(8,10,10.6)$ & $(18.8,20,22)$ \\
Touliu & $(14,15,16)$ & $(18.2,20,22)$ & $(10,12,13)$ & $(6,8,8.8)$ \\
Hsinchu & $(18.4,20,21)$ & $(9.6,12,13)$ & $(7.8,10,10.8)$ & $(14,15,16)$ \\
\hline
\end{tabular}

\section{Example 6.1: Transportation problem [16]}

Dali Company is the leading producer of soft drinks and low-temperature foods in Taiwan. Currently, Dali plans to develop the South-East Asian market and broaden the visibility of Dali products in the Chinese market. Notably, following the entry of Taiwan to the World Trade Organization, Dali plans to seek strategic alliance with prominent international companies and introduced international bread to lighten the embedded future impact. In the domestic soft drinks market, Dali produces tea beverages to meet demand from four distribution centers in Taichung, Chiayi, Kaohsiung, and Taipei, with production being based at three plants in Changhua, Touliu, and Hsinchu. According to the preliminary environmental information, Table 2 summarizes the potential supply available from the given three plants . The forecast demand from the four distribution centers as is shown Table 3. The profit of the company gained by each route is presented in Table 4. Table 5 summarizes the unit shipping cost for each route for the upcoming season. The environmental coefficient and related parameters generally are imprecise numbers with triangular possibility distributions over the planning horizon due to incomplete or unobtainable information. For example, the unavailable supply of the Changhua plant is $(7.2,8,8.8)$ thousand dozen bottles, the forecast demand of the Taichung distribution center is $(6.2,7,7.8)$ thousand dozen bottles, profit per dozen bottles for Changhua to Taichung is $(8,10$, 10.8) dollars and the transportation cost per dozen bottles for Changhua to Taichung is $(8,10,10.8)$ dollars. The management of Dali is initiating a study to maximize the profit as much as possible.

This present reality issue can be demonstrated to the accompanying FFLFP issue:

$\operatorname{Max} Z=\frac{\left\{\begin{array}{l}(8,10,10.8) \tilde{x}_{11}+(20.4,22,24) \tilde{x}_{12}+(8,10,10.6) \tilde{x}_{13}+(18.8,20,22) \tilde{x}_{14}+ \\ (14,15,16) \tilde{x}_{21}+(18.2,20,22) \tilde{x}_{22}+(10,12,13) \tilde{x}_{23}+(6,8,8.8) \tilde{x}_{24}+ \\ (18.4,20,21) \tilde{x}_{31}+(9.6,12,13) \tilde{x}_{32}+(7.8,10,10.8) \tilde{x}_{33}+(14,15,16) \tilde{x}_{34}\end{array}\right.}{\left\{\begin{array}{l}(1.5,2,2.5) \tilde{x}_{11}+(4,5,6) \tilde{x}_{12}+(1.3,2,2.5) \tilde{x}_{13}+(3,4,5) \tilde{x}_{14}+ \\ (2.5,3,4) \tilde{x}_{21}+(2,3,4) \tilde{x}_{22}+(2.3,3,4) \tilde{x}_{23}+(1.5,2,2.5) \tilde{x}_{24}+ \\ (3,4,5) \tilde{x}_{31}+(2,3,4) \tilde{x}_{32}+(1.5,2,2.7) \tilde{x}_{33}+(2,3,4) \tilde{x}_{34}\end{array}\right\}}$

Table 5 Shipping costs

\begin{tabular}{lllll}
\hline Source & \multicolumn{2}{l}{ Destination } & & \\
\cline { 2 - 5 } & Taichung & Chiayi & Kaohsiung & Taipei \\
\hline Changhua & $(1.5,2,2.5)$ & $(4,5,6)$ & $(1.3,2,2.5)$ & $(3,4,5)$ \\
Touliu & $(2.5,3,4)$ & $(2,3,4)$ & $(2.3,3,4)$ & $(1.5,2,2.5)$ \\
Hsinchu & $(3,4,5)$ & $(2,3,4)$ & $(1.5,2,2.7)$ & $(2,3,4)$ \\
\hline
\end{tabular}


S.t.

$\tilde{x}_{11}+\tilde{x}_{12}+\tilde{x}_{13}+\tilde{x}_{14} \leq(7.2,8,8.8)$

$\tilde{x}_{21}+\tilde{x}_{22}+\tilde{x}_{23}+\tilde{x}_{24} \leq(12,14,16)$

$\tilde{x}_{31}+\tilde{x}_{32}+\tilde{x}_{33}+\tilde{x}_{34} \leq(10.2,12,13.8)$

$\tilde{x}_{11}+\tilde{x}_{21}+\tilde{x}_{31} \geq(6.2,7,7.8)$

$\tilde{x}_{12}+\tilde{x}_{22}+\tilde{x}_{32} \geq(8.9,10,11.1)$

$\tilde{x}_{13}+\tilde{x}_{23}+\tilde{x}_{33} \geq(6.5,8,9.5)$

$\tilde{x}_{14}+\tilde{x}_{24}+\tilde{x}_{34} \geq(7.8,9,10.2)$

$\tilde{x}_{i j} \geq 0$, where $\tilde{x}_{i j}=\left(x_{i j}^{1}, x_{i j}^{2}, x_{i j}^{3}\right), i=1,2,3 ; j=1,2$, 3,4 .

Using Step 2 the problem (30) is changed into the MOLFP problem with three objective functions. Now using the Step3 and with regard to problem (20) we should first solve the problem (20). After using Step 3, we observe that the LFP problem has 7 constraints and 12 variables, while the LP problem proposed by Das et al.'s method [17] involves 45 constraints and 60 variables.

After solving this problem by using steps 4,5 and Sect. 4.1, we have:

$$
\tilde{x}=\left[\begin{array}{l}
(0,0,0), \\
(0,0,0.25), \\
(0,0,0.625), \\
(7.64,8,8), \\
(0,0,0), \\
(0,0,0), \\
(0,0,1.45), \\
(12,14,14), \\
(5.8,7,7.5), \\
(8.8,10,11.25), \\
(6.4,8,8), \\
(5.8,10,12.5) .
\end{array}\right]
$$

Presently the ideal solution of the issue may be forms as: $(\tilde{Z})$ proposed method $=\left(\left(Z_{1}\right), \quad\left(Z_{2}\right), \quad\left(Z_{3}\right)\right)=(2.26,4.64$, 9.48).

As we see that the issue has gotten solution is actually the ideal solution of the issue which start with the first issue and definitely worth those depending on existing calculation proposed by Das et al.'s strategy [16]. Be that as it may, by contrasting proposed results and existing strategy [16], it is a lot simpler, more effective and computational unpredictability more proficient.
Advantages of proposed method and result analysis

In this section, we talked about the fundamental focal points of the proposed technique over the current strategies for taking care of FFLFP issues.

- In our proposed technique, all the boundaries are nonnegative triangular fuzzy numbers which are not considered in the current strategies.

- In our detailed calculation, we utilize lexicographic technique which converts into three target capacities, which are anything but difficult to handle with exceptionally less requirements and factors and less computational weight taking care of FFLFP issues.

- We get the outcomes which likewise acquired by Das et al. [16] yet with simple and straightforward technique.

- Numbers of imperatives in our technique are the equivalent of the first model; however when Das et al. settled their model, the quantity of factors and imperatives is fundamentally expanded.

- Because of enormous increment in number of factors and limitations of Das et al. technique [16], the multifaceted nature of taking care of the issue by simplex increment and computation time will be increment certainly.

In the proposed technique the FFLFP issue transforms into a crisp LFP issue using LO method and that issue is changed over into LP issue by utilizing Charnes-Cooper strategy [1]. Presenting the problem crisp LP model and settled by utilizing LINGO Version 11.0. Agreeing an optimal solution by both the techniques is delineated in Figs. 1 and 2.

- In our proposed model, our results are better than existing results. In our model, we introduced a new lexicographic order method for solving fuzzy LFP problem and transformed into a crisp LFP problem.

- In Figs. 1 and 2, we have compared our proposed technique with other existing technique, we have found that the objective value of our proposed method is maximum than to the existing method [16].

- Our model is very simple and efficient than existing method [16].

- Our model is applied in real life problem and also large scale problem.

\section{Conclusions}

In this paper, another tackling system has been proposed to take care of the FFLFP issue. Here we consider all boundaries of the issue are nonnegative triangular fuzzy numbers. We 


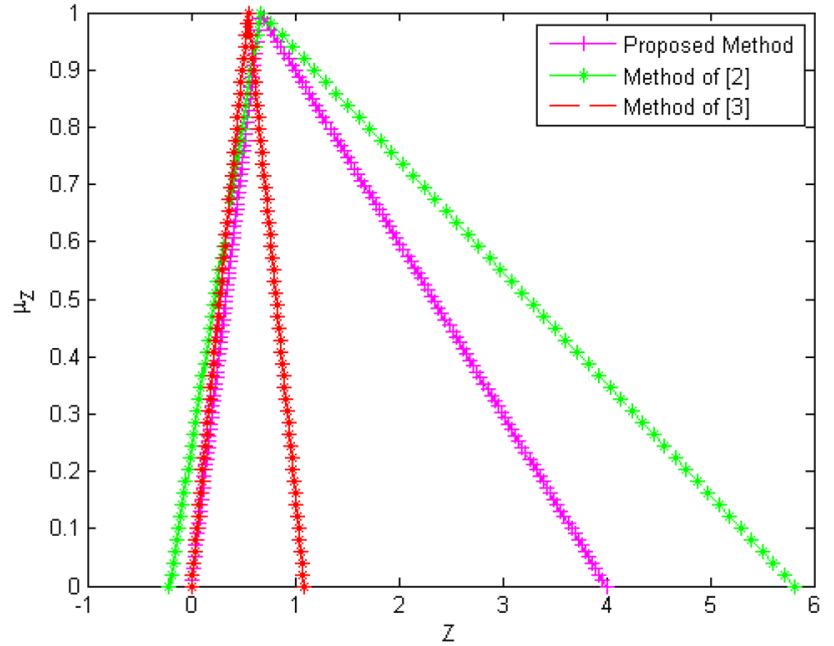

Fig. 1 Membership elements of the optimal solution of current technique and existing technique $[15,16]$

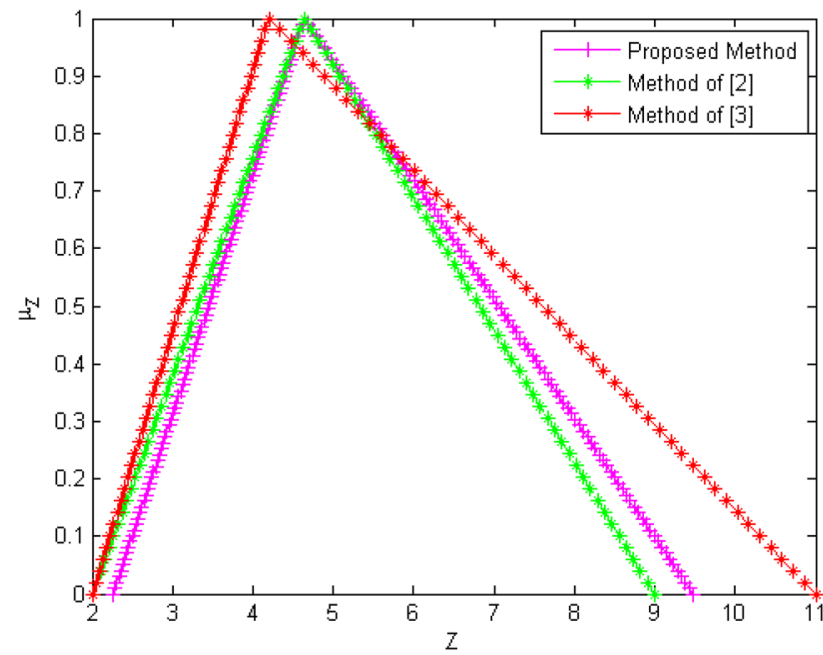

Fig. 2 Membership elements of the optimal solution by the current technique and existing strategy $[15,16]$

also derived some crisp LFP problem from the FFLFP problem which is equivalent to the problem. However, in crisp LFP problem involve lesser constraints and variables than some other problems. It is our conviction that the proposed technique arrangement of FFLFP issue, all things considered, the issue just as a basic issue might be of significant enthusiasm for mathematician working in this field. A simple example and one real life problem has been provided to verify the clarity of the proposed approach and to understand its effectiveness along with the computational complexity and compared with Das et al.'s [16] method. The extended form of the proposed approach can be formulated to solve unrestricted triangular fuzzy umber. The concept discussed in this study is expected to be useful in real life problems such as in the field of agriculture, inventory problems, production planning, transportation problem etc. where linear fractional problems arise with fuzzy parameters.
This investigation can be emerged not less than two headings. From one viewpoint, the proposed technique in this paper may be extended to solve FFLFP problem involving all kinds of triangular fuzzy numbers (non-negative and non-positive) is exceptionally intriguing later on research. Then again, the proposed technique in this investigation is not applicable to FLFP issues with trapezoidal fuzzy numbers. The speculation of the proposed strategy to beat this deficiency is left for the next work.

\section{Declarations}

Conflict of interest The authors state that they do not have any conflict of interest.

Open Access This article is licensed under a Creative Commons Attribution 4.0 International License, which permits use, sharing, adaptation, distribution and reproduction in any medium or format, as long as you give appropriate credit to the original author(s) and the source, provide a link to the Creative Commons licence, and indicate if changes were made. The images or other third party material in this article are included in the article's Creative Commons licence, unless indicated otherwise in a credit line to the material. If material is not included in the article's Creative Commons licence and your intended use is not permitted by statutory regulation or exceeds the permitted use, you will need to obtain permission directly from the copyright holder. To view a copy of this licence, visit http://creativecomm ons.org/licenses/by/4.0/.

\section{References}

1. Charnes A, Cooper WW (1962) Programming with linear fractional functionals, naval. Res Logist Q 9:181-186

2. Pop B, Stancu-Minasian IM (2008) A method of solving fully fuzzified linear fractional programming problems. J Appl Math Comput 27:227-242

3. Stanojevic B, Stancu-Minasian IM (2012) Evaluating fuzzy inequalities and solving fully fuzzified linear fractional programs. Yugoslav J Oper Res 1:41-50

4. Stanojevic B, Stancu-Minasian IM (2009) On solving fuzzified linear fractional programs. Adv Model Optim 11:503-523

5. Dutta D, Tiwari RN, Rao JR (1992) Multiple objective linear fractional programming - a fuzzy set theoretic approach. Fuzzy Sets Syst 52:39-45

6. Stancu-Minasian IM, Pop B (2003) On a fuzzy set approach to solving multiple objective linear fractional programming problem. Fuzzy Sets Syst 134:397-405

7. Buckley JJ, Feuring T (2000) Evolutionary algorithm solution to fuzzy problems: fuzzy linear programming. Fuzzy Sets Syst 109:35-53

8. Zadeh LA (1965) Fuzzy sets. Inf Control 8:338-353

9. Chakraborty M, Gupta S (2002) Fuzzy mathematical programming for multi objective linear fractional programming problem. Fuzzy Sets Syst 125:335-342

10. Toksari MD (2008) Taylor series approach to fuzzy multi objective linear fractional programming. Inf Sci 178:1189-1204

11. Sakawa M, Yano H (1988) An interactive fuzzy satisficing method for multiobjective linear fractional programming problems. Fuzzy Sets Syst 28:129-144 
12. Sakawa M, Yano H, Takahashi J (1992) Pareto optimality for multiobjective linear fractional programming problems with fuzzy parameters. Inf Sci 63:33-53

13. Ezzati R, Khorram E, Enayati R (2015) A new algorithm to solve fully fuzzy linear programming problems using MOLP problem. Appl Math Model 39:3183-3193

14. Ali E (2021), An effective computational attempt for solving fully fuzzy linear programming using MOLP problem. J Ind Prod Eng (in press)

15. Das S, Edalatpanah SA, Mandal T (2018) A proposed model for solving fuzzy linear fractional programming problem: numerical point of view. J Comput Sci. https://doi.org/10.1016/j.jocs.2017.1 2.004

16. Das S, Edalatpanah SA, Mandal T (2017) A new approach for solving fully fuzzy linear fractional programming problems using the multi-objective linear programming. RAIRO Oper Res 51:285-297

17. Das S, Mandal T, Edalatpanah SA (2016) A mathematical model for solving fully fuzzy linear programming problem with trapezoidal fuzzy numbers. Appl Intell 46:509-519

18. Das S, Mandal T (2017) A new model for solving fuzzy fuzzy linear fractional programming problem with ranking function. J Appl Res Ind Eng 4:89-96

19. Das S, Mandal T (2017) A MOLFP method for solving linear fractional programming under fuzzy environment. Int J Res Ind Eng 6:202-213

20. Das S (2017) Modified method for solving fully fuzzy linear programming problem with triangular fuzzy numbers. Int J Res Ind Eng 6:293-311

21. Schaible S (1976) Fractional programming I: duality. Manag Sci 22:658-667

22. Veeramani C, Sumathi M (2014) Solving the linear fractional programming problem in a fuzzy environment: numerical approach. Appl Math Model 40:6148-6164

23. Stanojevic B, Stanojevic M (2012) Parametric computation of a fuzzy set solution to a class of fuzzy linear fractional optimization problems. Fuzzy Optim Decis Mak 15:435-455
24. Veeramani C, Sumathi M (2014) Fuzzy mathematical programming approach for solving fuzzy linear programming problem. RAIRO Oper Res 48:109-122

25. Stanojevic B, Stanojevic M (2013) Solving method for linear fractional optimization problem with fuzzy coefficients in the objective function. Int J Comput Commun Control 8:136-145

26. Das SK, Edalatpanah SA (2020) A new ranking function of triangular neutrosophic number and its application in integer programming. Int J Neutosophic Sci 4(2):82-92

27. Das S, Dash JK (2020) Modified solution for neutrosophic linear programming problems with mixed constraints. Int J Res Ind Eng 9(1): $13-24$

28. Das S, Mandal T, Behera D (2019) A new approach for solving fully fuzzy linear programming problem. Int J Math Oper Res 15(3):296-309

29. Das S, Mandal T, Edalatpanah SA (2020) A new method for solving linear fractional programming problem with absolute value functions. Int J Oper Res 36(4):455-466

30. Thippa Ready G, Gao XZ (2021) An efficient attribute reduction and fuzzy logic classifier for heart disease and diabetes prediction. Recent Adv Comput Sci Commun 14(1):158-165

31. Reddy GT, Reddy MPK, Lakshmanna Ket al (2020) Hybrid genetic algorithm and a fuzzy logic classifier for heart disease diagnosis. Evol Intell 13:185-196

32. Das S, Chakraborty A (2021) A new approach to evaluate linear programming problem in pentagonal neutrosophic environment. Complex Intell Syst 7:101-110

Publisher's Note Springer Nature remains neutral with regard to jurisdictional claims in published maps and institutional affiliations. 